\title{
Low Back Pain and Internet: Infopollution
}

\author{
Yavuz SAMANCI ${ }^{1}$, Suat Erol CELIK ${ }^{2}$ \\ ${ }^{1}$ Istanbul Training and Research Hospital, Neurosurgery Clinic, Istanbul, Turkey \\ ${ }^{2}$ Okmeydani Training and Research Hospital, Neurosurgery Clinic, Istanbul, Turkey
}

\section{ABSTRACT}

AIM: An increasing number of patients engage in health information seeking via the internet. We aimed to determine the quality of information on the internet for treatment of three common neurosurgical conditions associated with low back pain using the DISCERN ${ }^{\circledR}$ instrument.

MATERIAL and METHODS: The search phrases "lumbar disc herniation (LDH) treatment", "lumbar spinal stenosis (LSS) treatment" and "lumbar spondylolisthesis (LSL) treatment" were searched in the Google ${ }^{\circledR}$ search engine using the simple searching method. The first 30 websites were evaluated for website authors (healthcare, news, personal, physician, and unidentified), and DISCERN ${ }^{\circledR}$ Scores using 15 key questions representing a separate quality criterion plus an overall quality rating. Each site was scored independently by two observers.

RESULTS: Of 90 links retrieved, a total of 83 websites were used for analysis. The physician authors were ranked first (39.3\%) in the search results. Only $3.6 \%$ of the websites had clear aims, and the information was relevant in $6 \%$. Seventy-two (86.7\%) websites had no sources of evidence for the information mentioned. The information was completely balanced and unbiased in only 8 (9.6\%) websites. Fifty-one (61.5\%) websites had no described benefits for any of the treatments and only $2(2.4 \%)$ websites described a risk for each treatment. Only $6(7.2 \%)$ websites were found to be useful and appropriate sources of information about treatment choices. The DISCERN ${ }^{\circledR}$ scores were not significantly different between all author groups $(p=0.713)$.

CONCLUSION: The information on the treatment options of LDH, LSS and LSL on the internet is not useful or appropriate regarding treatment choices. Neurosurgeons should be aware of this inconsistency.

KEYWORDS: Internet, Lumbar disc herniation, Lumbar spinal stenosis, Lumbar spondylolisthesis, Neurosurgery

ABBREVIATIONS: LBP: Low back pain, LDH: Lumbar disc herniation, LSS: Lumbar spinal stenosis, LSL: Lumbar spondylolisthesis, SPSS: Statistical Package for the Social Sciences

\section{INTRODUCTION}

$\mathrm{L}$ ow back pain (LBP) is extraordinarily common and is the second most common reason that people visit La healthcare provider (10). Up to $84 \%$ of the general population will experience LBP at some point in their lives (11), and the majority of LBP episodes will resolve within two to four weeks. Although most of the patients are never diagnosed with a specific disorder, mechanical causes of LBP for which a patient will be referred to a neurosurgeon mostly include lumbar disc herniation (LDH), lumbar spinal stenosis (LSS) and lumbar spondylolisthesis (LSL). Many therapeutic options are available for patients with these three conditions, including oral drugs, physical measures (bed rest, activity modification, exercise, manipulation, local heat, local cold and corsets), injection drugs, stimulation, and surgery.

An increasing number of healthcare professionals and patients engage in interactive health communication, which is defined as "the interaction of an individual-consumer, patient, 
caregiver or professional-with or through an electronic device or communication technology to access or transmit health information or to receive guidance and support on a health-related issue" by Robinson et al. (24). Patient use of the internet for health information is large and growing as more than 70,000 websites provide health information (9). Seventy-seven percent of patients seek health information for themselves prior to consultation with their physicians (4). Although patient online health-information seeking might lead to better-informed decisions by patients, better and more tailored treatment decisions, stronger physicianpatient relationships, and increased patient compliance and satisfaction (1), online health information might also cause diminished medical outcomes due to information overload (18), disorganization (17), searching difficulties (7), inaccessible or overly technical language (16), lack of user friendliness (21), lack of permanence (20), and inaccurate, misleading and dangerous information, what we call "Infopollution", on websites $(17,25)$.

The aim of this study was to identify the quality of information presented on Turkish websites regarding the treatment of LDH, LSS and LSL, and its role in patient education by evaluating the author classification and DISCERN ${ }^{\circledR}$ scores of the searched websites.

\section{MATERIAL and METHODS}

The phrases "lumbar disc herniation treatment", "lumbar spinal stenosis treatment" and "lumbar spondylolisthesis treatment" were searched in the Google ${ }^{\circledR}$ search engine, as it is the most commonly used search engine in Turkey (19). The search phrases were intended to mimic the possible searching behavior of a patient who had a consultation with a physician at the outpatient clinic for a proposed surgery and who had limited medical or internet knowledge. The Google ${ }^{\circledR}$ search engine listed the websites according to their relevancy scores. As a study (5) on Google ${ }^{\circledR}$ traffic showed that the first 30 results garnered $97.4 \%$ percent of all traffic from the average search, the first 30 websites identified by the Google ${ }^{\circledR}$ search engine underwent further in-depth review.

Each website was classified according to the website author; namely healthcare, news, personal, physician, and unidentified (Table I).

The websites were then evaluated by using the DISCERN ${ }^{\circledR}$ instrument (Table II) (3). It is an instrument, or tool, which has been designed to help users of consumer health information judge the quality of written information about treatment choices. It consists of 15 key questions plus an overall quality rating. The questions are organized in three sections as follows: Section 1 (Questions 1-8) addresses the reliability and helps decide whether the information can be trusted as a source of information about treatment choices, section 2 (questions 9-15) focuses on the specific details of the information about treatment choices, and section 3 (question 16) consists of the overall quality rating of the assessor at the end of the instrument. Each question is rated on a 5-point scale ranging from No to Yes. Each site was scored independently by two observers (Y.S., S.E.C). Cohen's Kappa was run to determine the inter-observer reliability.

All statistical analyses were performed using the Statistical Package for the Social Sciences (SPSS) software, version 22.0. Statistically significant differences between groups were analyzed with analysis of variance and were defined with a $p$ value of less than 0.05 .

\section{- RESULTS}

Of the 90 links retrieved, 89 (98.9\%) were assessed. One website from the LSL group was a dead website. Of those 89 websites, six $(6.7 \%)$ were unrelated to treatment options. Therefore, a total of 83 websites were used for analysis.

Of the five author classifications, the physician (39.3\%) authors ranked first, followed by news $(21.3 \%)$, healthcare (18\%), personal (14.6\%) and unidentified (6.7\%) authors. However, unlike the other two groups, news authors were more common in the LDH group. Author distributions among three groups are shown in Table III.

Regarding section 1 scores, only three (3.6\%) of all the websites had clear aims, and all provided the expected information. These websites were all in the LDH group. Nine (10.8\%) websites had unclear or incomplete aims. The information was relevant in five (6\%) websites, and not at all relevant in thirty $(36.2 \%)$ websites. While the sources of evidence were clear to some extent in eleven (13.3\%) websites, the remaining seventy-two (86.7\%) websites had no sources of evidence for the information mentioned. Of all websites, sixty-two $(74.7 \%)$ had no clear dates for all acknowledged sources. The information was completely balanced and unbiased in only eight $(9.6 \%)$ websites. No additional sources of information were provided in eighty-one $(97.6 \%)$ websites. Only three (3.6\%) websites included a clear reference to any uncertainty regarding treatment choices.

Regarding section 2 scores, nine (10.8\%) websites had the description of each treatment, including details of how treatment works. While only six (7.2\%) websites had a described benefit for each treatment, fifty-one (61.5\%) websites had no described benefits for any of the treatments. Regarding

Table I: Website Author Classification

\begin{tabular}{ll}
\hline Author & Definition \\
\hline Healthcare & $\begin{array}{l}\text { Websites affiliated with a government or } \\
\text { private healthcare facility }\end{array}$ \\
\hline News & $\begin{array}{l}\text { Websites affiliated with organizations } \\
\text { dealing with news }\end{array}$ \\
\hline Personal & $\begin{array}{l}\text { Non-physicians with no institutional or } \\
\text { organizational affiliation }\end{array}$ \\
\hline Physician & $\begin{array}{l}\text { Individual physicians with no healthcare } \\
\text { facility affiliation }\end{array}$ \\
\hline Unidentified & $\begin{array}{l}\text { Dead links or otherwise unidentifiable } \\
\text { websites }\end{array}$ \\
\hline
\end{tabular}


Table II: The DISCERN ${ }^{\circledR}$ Instrument

Question 1: Are the aims clear?

Question 2: Does it achieve its aims?

Question 3: Is it relevant?

Question 4: Is it clear what sources of information were used to compile the publication (other than the author or producer)?

Question 5: Is it clear when the information used or reported in the publication was produced?

Question 6: Is it balanced and unbiased?

Question 7: Does it provide details of additional sources of support and information?

Question 8: Does it refer to areas of uncertainty?

Question 9: Does it describe how each treatment works?

Question 10: Does it describe the benefits of each treatment?

Question 11: Does it describe the risks of each treatment?

Question 12: Does it describe what would happen if no treatment is used?

Question 13: Does it describe how the treatment choices affect overall quality of life?

Question 14: Is it clear that there may be more than one possible treatment choice?

Question 15: Does it provide support for shared decision-making?

Question 16: Based on the answers to all of the above questions, rate the overall quality of the publication as a source of information about treatment choices

Table III: Distribution of Website Authors

\begin{tabular}{lccc}
\hline Author $(\mathrm{n}=\mathbf{8 9})$ & LDH $(\mathrm{n}=\mathbf{3 0})$ & LSS $(\mathrm{n}=\mathbf{3 0})$ & LSL $(\mathrm{n}=\mathbf{2 9})$ \\
\hline Physician $(\mathrm{n}=35)$ & 5 & 17 & 13 \\
\hline News $(\mathrm{n}=19)$ & 9 & 5 & 5 \\
\hline Healthcare $(\mathrm{n}=16)$ & 7 & 4 & 5 \\
\hline Personal $(\mathrm{n}=13)$ & 7 & 2 & 4 \\
\hline Unidentified $(\mathrm{n}=6)$ & 2 & 2 & 2 \\
\hline
\end{tabular}

LDH: Lumbar disc herniation, LSS: Lumbar spinal stenosis, LSL: Lumbar spondylolisthesis.

mentioned risks, only two (2.4\%) websites described a risk for each treatment and no risks were described in sixty-six (79.5\%) websites. Fifteen (18.1\%) websites had a clear description of a risk or a benefit associated with any "no treatment" option and only two (2.4\%) websites included a clear reference to overall quality of life in relation to any of the treatment choices mentioned. Although twenty-one (25.3\%) made it very clear that there may be more than one possible treatment choice, only five $(23.8 \%)$ of those twenty-one websites provided very good support for shared decision-making by advising readers to consult doctors, family, fellow sufferers.

Regarding section 3 scores, based on the answers to all of the above questions, only six (7.2\%) websites, three in LDH group and three in the LSS group, were found to be a useful and appropriate source of information about treatment choices. Mean DISCERN ${ }^{\circledR}$ scores of section 1,2 and 3 are shown in Figure 1.

There was an almost perfect agreement between the two observers $(\mathrm{K}=0.96)$.

Although the physician and healthcare author groups had higher scores in section $2(2.0 \pm 0.52$ and $2.2 \pm 0.45$, respectively) and section $3(1.7 \pm 1.32$ and $1.8 \pm 1.44)$, the difference between all author groups was not statistically significant $(p=0.713)$ (Figure 2).

\section{DISCUSSION}

The rapid development in internet began with increased widespread diffusion of personal computers and applicability of internet use $(8,22)$, and this triggered an information revolution of unprecedented magnitude (13). Approximately $63 \%$ of internet users in the U.S. have sought health information (22), and there are more than 70,000 websites providing health information on the internet (9). Searches are mostly performed following a diagnosis (2), and intended for obtaining information related to a physical illness (23). However, the multiplicity in the number of websites might cause accessing inaccurate, misleading and dangerous information from uncontrolled and unmonitored websites (6). In parallel to this, $92.8 \%$ of websites were of low-to-moderate quality, with $77.1 \%$ of websites being unlikely to be of any benefit in our study. Only $7.2 \%$ of websites were found to be appropriate source of information about treatment choices. 


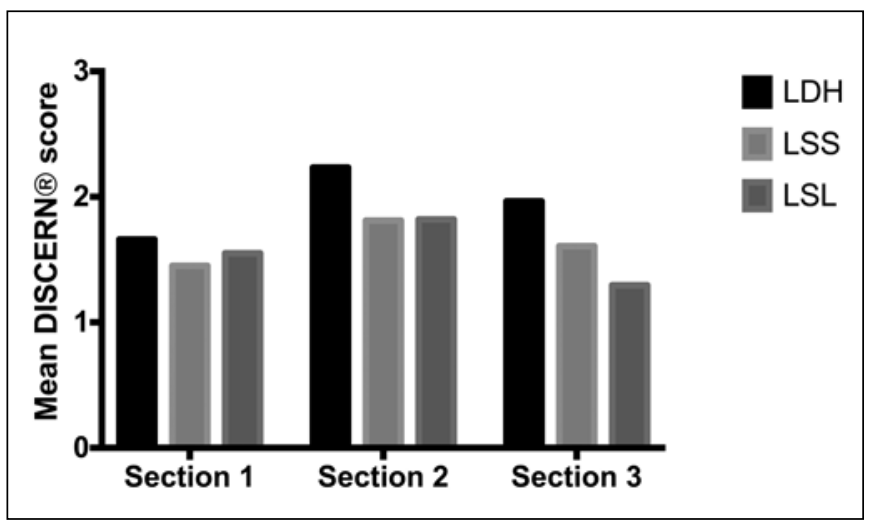

Figure 1: The mean DISCERN ${ }^{\circledR}$ scores of section 1, 2 and 3. (LDH: Lumbar disc herniation, LSS: Lumbar spinal stenosis, LSL: Lumbar spondylolisthesis).

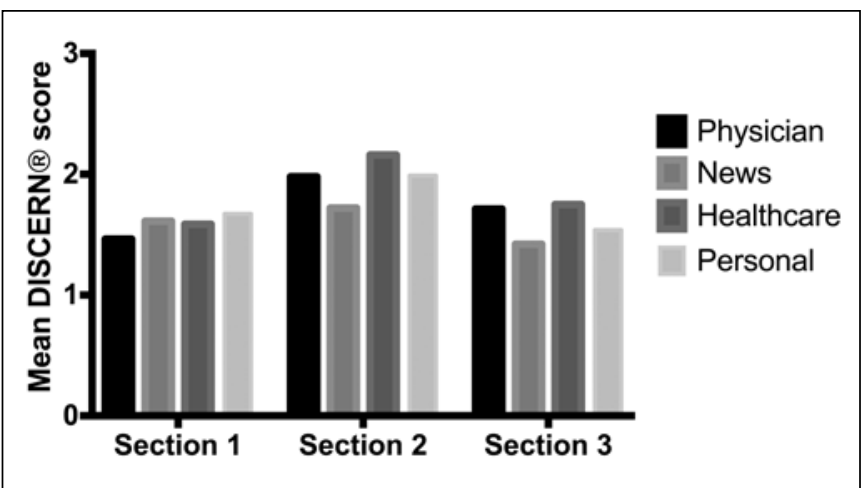

Figure 2: The mean DISCERN ${ }^{\circledR}$ scores of section 1,2 and 3 in all author groups.

Google ${ }^{\circledR}$ provided $67.5 \%$ of global search queries in 2014 and it ranked first with the usage of about $94.9 \%$ in Turkey (19). Regarding this, Google ${ }^{\circledast}$ search engine was used to search for information in this study, as it is one of the most common ways for internet users to seek information on the internet (12). We designed the search method so as to mimic the possible searching behavior of a patient with a limited medical or internet knowledge. This type of search often yields more irrelevant websites than in case of a structured and aimed searching. However, of all accessible websites, only $6.7 \%$ were unrelated to treatment options, and this rate can be ignored compared to the $93.3 \%$ relevance rate.

As previously stated by Lunik (15) and Lacroix et al. (14), there is no arbiter of truth on internet and no quality filter, meaning that anyone can develop a website and authorship can be misleading as anyone can claim medical expertise. In our study, the physician and healthcare author groups had higher scores compared to other author groups but, unlike what was expected, the difference between all author groups was not statistically significant. Interestingly, $74.5 \%$ of websites with physician and healthcare authors provided information with serious shortcomings. This might be due to aforementioned incorrect authorship claiming, or worse, intentionally misleading the patients.
Finally, the website of the Turkish Neurosurgical Society was detected within the first 30 websites only in LDH search results, with a rank of \#27. It ranked \#65 in LSS search results and \#88 in LSL search results. Our Society should pay attention to provide a clearly marked patient information page on its website in order to improve the quality of medical information on internet. More effort should be made to position this website on the first page of search results, as the first pages garner $91.5 \%$ of all search traffic (5). This can be achieved by providing more links pointing to that website or keywords that people will search for.

\section{CONCLUSION}

Information about LDH, LSS and LSL on websites accessed through simple searching methods is not a useful or appropriate source of information about treatment choices. In order to achieve the advantages of interactivity and information tailoring offered by websites, neurosurgeons and physicians dealing with LDH, LSS and LSL should be aware of the quality of information on internet.

\section{- REFERENCES}

1. Ayonrinde O: Patients in cyberspace: Information or confusion? Postgrad Med J 74(874):449-450, 1998

2. Boyer C, Selby M, Appel RD: The health on the net code of conduct for medical and health web sites. Stud Health Technol Inform 52 Pt 2:1163-1166, 1998

3. Charnock D, Shepperd S, Needham G, Gann R: DISCERN ${ }^{\circledR}$ : An instrument for judging the quality of written consumer health information on treatment choices. J Epidemiol Community Health 53(2):105-111, 1999

4. Chi-Lum B: Friend or foe? Consumers using the internet for medical information. J Med Pract Manage 14(4):196-198, 1999

5. Chitikalnsights: The Value of Google Result Positioning. Available from:http://info.chitika.com/uploads/4/9/2/1/49215843/ chitikainsights-valueofgoogleresultspositioning.pdf [last accessed 2016 June 26], 2013

6. Cline RJ, Haynes KM: Consumer health information seeking on the internet: The state of the art. Health Educ Res 16(6):671692, 2001

7. DeGeorges KM: Taming the World Wide Web. If everything is on the Web, why can't I find anything? AWHONN Lifelines 2(4):50-52, 1998

8. Eng TR, Maxfield A, Patrick K, Deering MJ, Ratzan SC, Gustafson DH: Access to health information and support: A public highway or a private road? JAMA 280(15):1371-1375, 1998

9. Grandinetti DA: Doctors and the Web. Help your patients surf the Net safely. Med Econ 77(5):186-188, 194-186, 201, 2000

10. Hart LG, Deyo RA, Cherkin DC: Physician office visits for low back pain. Frequency, clinical evaluation, and treatment patterns from a U.S. national survey. Spine (Phila Pa 1976) 20(1):11-19, 1995 
11. Hoy D, Bain C, Williams G, March L, Brooks P, Blyth F, Woolf A, Vos T, Buchbinder R: A systematic review of the global prevalence of low back pain. Arthritis Rheum 64(6):20282037, 2012

12. Huberman BA, Pirolli PLT, Pitkow JE, Lukose RM: Strong regularities in world wide web surfing. Science 280(5360):9597, 1998

13. Jadad AR, Gagliardi A: Rating health information on the internet: Navigating to knowledge or to Babel? JAMA 279(8):611-614, 1998

14. Lacroix EM, Backus JE, Lyon BJ: Service providers and users discover the internet. Bull Med Libr Assoc 82(4):412-418, 1994

15. Lunik MC: What's in there for me? The internet for pharmacists. Pharm Pract Manag Q 17(4):37-47, 1998

16. McGrath I: Information superhighway or information traffic jam for healthcare consumers? Clin Perform Qual Health Care 5(2):90-93, 1997

17. McKinley J, Cattermole H, Oliver CW: The quality of surgical information on the internet. J R Coll Surg Edinb 44(4):265-268, 1999

18. McLellan F: "Like hunger, like thirst": Patients, journals, and the internet. Lancet 352 Suppl 2:SII39-II43, 1998

19. NetApplications: Market Share Statistics for internet Technologies. Available from: http://www.netmarketshare. com (last accessed 2016 June 26), 2014
20. O'Mahony B: Irish healthcare web sites: A review. Ir Med J 92(4):334-337, 1999

21. Pennbridge J, Moya R, Rodrigues L: Questionnaire survey of California consumers' use and rating of sources of health care information including the internet. West J Med 171(5-6):302305, 1999

22. PewResearchCenter: More online, doing more: 16 million newcomers gain internet access in the last half of 2000 as women, minorities, and families with modest incomes continue to surge online. Available from: http://www.pewinternet.org (last accessed 2016 June 26), 2001

23. PewResearchCenter: The online health care revolution: How the Web helps Americans take better care of themselves. Available from: http://www.pewinternet.org (last accessed 2016 June 26), 2000c

24. Robinson TN, Patrick K, Eng TR, Gustafson D: An evidencebased approach to interactive health communication: $A$ challenge to medicine in the information age. Science panel on interactive communication and health. JAMA 280(14):12641269, 1998

25. Silberg WM, Lundberg GD, Musacchio RA: Assessing, controlling, and assuring the quality of medical information on the internet: Caveant lector et viewor-Let the reader and viewer beware. JAMA 277(15):1244-1245, 1997 